\title{
Profiling of koumiss microbiota and organic acids and their effects on koumiss taste
}

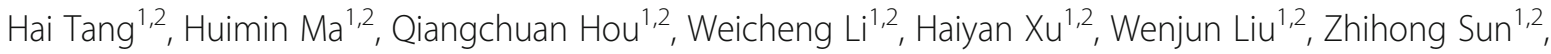
Halatu Haobisi ${ }^{3}$ and Bilige Menghe $e^{1,2^{*}}$

\begin{abstract}
Background: Koumiss is a naturally fermented mare's milk. Over recent decades, numerous studies have revealed the diversity of lactic acid bacteria in koumiss. However, there is limited information available regarding its secondary major component yeast profile.

Results: A total of 119 bacterial and 36 yeast species were identified among the 14 koumiss samples. The dominant bacterial species in koumiss were Lactobacillus helveticus, Lactobacillus kefiranofaciens, Lactococcus lactis, Lactococcus raffinolactis, and Citrobacter freundii. The main yeast species were Dekkera anomala, Kazachstania unispora, Meyerozyma caribbica, Pichia sp.BZ159, Kluyveromyces marxianus, and uncultured Guehomyces. The bacterial and yeast Shannon diversity of the Xilinhaote-urban group were higher than those of the Xilingol-rural group. The most dominant organic acids were lactic, acetic, tartaric, and malic acids. Lactic acid bacteria species were mostly responsible for the accumulation of those organic acids, although Kazachstania unispora, Dekkera anomala, and Meyerozyma caribbica may also have contributed. Redundancy analysis suggested that both bacteria and yeast respond to koumiss flavor, such as Lactobacillus helveticus and Dekkera anomala are associated with sourness, astringency, bitterness, and aftertaste, whereas Lactococcus lactis and Kazachstania unispora are associated with umami.
\end{abstract}

Conclusions: Our results suggest that differences were observed in koumiss microbiota of Xilinhaote-urban and Xilingol-rural samples. The biodiversity of the former was higher than the latter group. Positive or negative correlations between bacteria and yeast species and taste also were found.

Keywords: Bacterial diversity, Yeast diversity, Organic acids, Taste, Koumiss

\section{Background}

Koumiss is a naturally fermented mare's milk with a long history of consumption in the Mongolian steppes. Its name is derived from the Kumanese, who survived as a Kumane River tribe on the central Asian steppes until 1235. When fully renneted, the proteins in horse milk

\footnotetext{
* Correspondence: mhblg@163.com

'Key Laboratory of Dairy Biotechnology and Engineering, Ministry of Education, Inner Mongolia Agricultural University, Hohhot 010018, People's Republic of China

${ }^{2}$ Key Laboratory of Dairy Products Processing, Ministry of Agriculture, Inner Mongolia Agricultural University, Hohhot 010018, People's Republic of China Full list of author information is available at the end of the article
}

form no visible curd [1], and it is ivory or slightly yellow in color with a sharp acidic and alcoholic flavor [2]. The flavor characteristics of koumiss were recorded in the Mongolian medical book as follows: "milk taste sour, slight sweet, a bit acerbity". Koumiss has been used in the treatment of some diseases in Mongolian traditional medicine [3]. Koumiss is a typical yeast-lactic fermented product that is made with specific strains of lactic acid bacteria (LAB) and yeast [4]. The Lactobacillus strains isolated from koumiss show good performance as probiotics [5]. Over recent decades, numerous studies using culture-dependent and -independent methods have revealed the diversity of LAB in koumiss [6-8]. However, 
there is limited information available regarding its yeast profile $[9,10]$ or sensory characteristics.

The flavor of dairy products is directly and indirectly derived from factors such as the raw milk quality, production process, and activities of diverse microbial populations [11]. In particular, the rich bacterial and yeast microbiota of yeast-lactic fermented milk are responsible for the unique flavor properties [12]. Usually, biodiversity of naturally fermented milk is varied with sample types and geographical origins $[8,13]$. Moreover, koumiss produced by herdsmen is particularly sour; this type of koumiss was thought to have the most medicinal value, but its taste is unacceptable to some consumers. Therefore, we collected samples from the city (Xilinhaote-urban group) and the surrounding rural area (Xilingol-rural group) to study the differences in koumiss microbiota.

During milk fermentation, the concentrations of some organic acids (lactic and acetic acid) increase, while those of other organic acids (citric acid, etc.) decrease [14]. Short-chain carboxylic acids are one of the most important differential contributors to the flavor of milk products. These acids are derived from lipolysis, carbohydrate metabolism, or amino acid metabolism [15, 16]. We assessed the organic acid content of koumiss.

Chemical composition analysis provides quantitative data that are not instructive in terms of analysis of taste; therefore, we employed a taste-sensing system with advanced taste sensors that were developed based on correlations with human sensory scores, and are applied in assessments of milk and beverage products [17-20]. Traditional fermented foods may be significantly improved by using starter cultures selected based on multiple considerations [21]. The present study assessed the correlations among organic acid content, taste, and koumiss microbiota to provide data to guide the development of a koumiss starter culture, with improved and controlled fermentation, for commercial use.

\section{Results}

Koumiss bacteria and yeast: composition and diversity Sequencing of the full-length 16S rRNA gene using the SMRT technology revealed high taxonomical resolution of the Xilinhaote-urban and Xilingol-rural groups at the species level (Fig. 1). The bacterial Shannon diversity index of the Xilinhaote-urban group was slightly higher than that of the Xilingol-rural group $(p=0.068)$, whereas the yeast Shannon diversity index was higher in Xilinhaote-urban than Xilingol-rural samples $(p=0.001)$ (Fig. 2). The most diverse bacterial species was Lactobacillus lactis (L. lactis); it had a lower abundance in Xilingol-rural samples than Xilinhaote-urban samples $(p=0.012)$. There were no significant differences in dominant yeast species abundance.

A total of 119 bacterial and 36 yeast species were identified among the 14 koumiss samples. The bacterial and yeast species with a relative abundance of $>1 \%$ are summarized (Tables 1 and 2) and presented (Figs. 3 and 4). The homotypic synonym of Kazachstania unispora (K. unispora) is Saccharomyces unisporus. Yeast species with fluctuations in abundance of $<5 \%$ include Meyerozyma caribbica (M. caribbica), Pichia sp.BZ159 (P. BZ159), and uncultured Guehomyces.

\section{Organic acids in koumiss}

The organic acids detected in koumiss included oxalic, tartaric, malic, lactic, acetic, citric, and succinic acid, with an average content of $6.54 \mathrm{~g} / \mathrm{L}$. The most dominant acids across all samples were lactic $(1.42 \mathrm{~g} / \mathrm{L}, 21.7 \%)$, acetic $(1.78 \mathrm{~g} / \mathrm{L}, 27.3 \%)$, tartaric $(1.26 \mathrm{~g} / \mathrm{L}, 19.2 \%)$, and malic $(1.39 \mathrm{~g} / \mathrm{L}, 21.2 \%)$ acids (Fig. 5a). The mean concentration of citric acid was higher in Xilinhaote-urban samples $(0.39 \mathrm{~g} / \mathrm{L})$ than Xilingol-rural samples $(0.06 \mathrm{~g} / \mathrm{L}, p<0.05)$.

All major organic acids were analyzed by principal component analysis. The first two components explained $69.90 \%$ of the variance. PC1 accounted for $51.32 \%$ of the variance and well-explained the separation of the Xilinhaote-urban and Xilingol-rural samples. Xilinhaoteurban samples formed a tighter cluster than the Xilingolrural samples, which were more diffuse along PC1 (Fig. 5b).

\section{The potential symbiotic relationship between yeasts and LAB}

In addition to the associations of bacterial and yeast species compositions, a correlation between the abundance
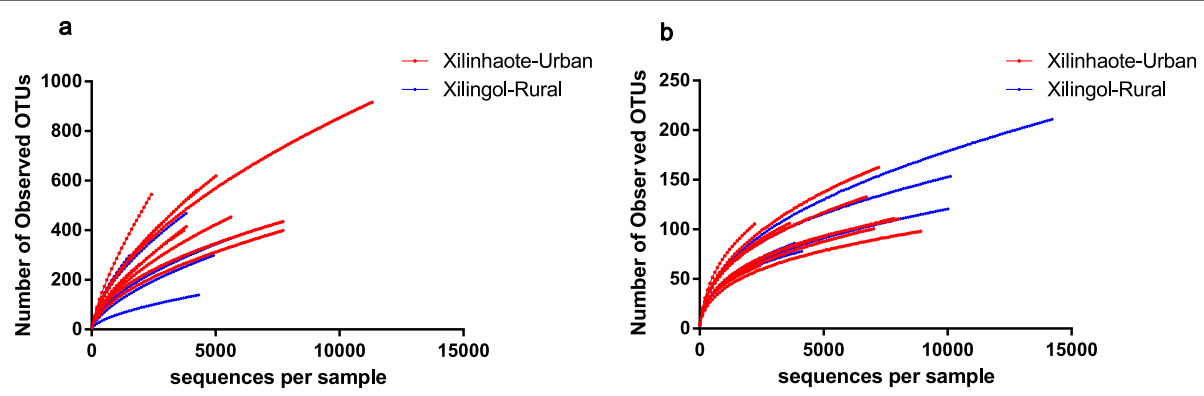

Fig. 1 Rarefaction curve of the bacterial (a) and yeast (b) diversity 

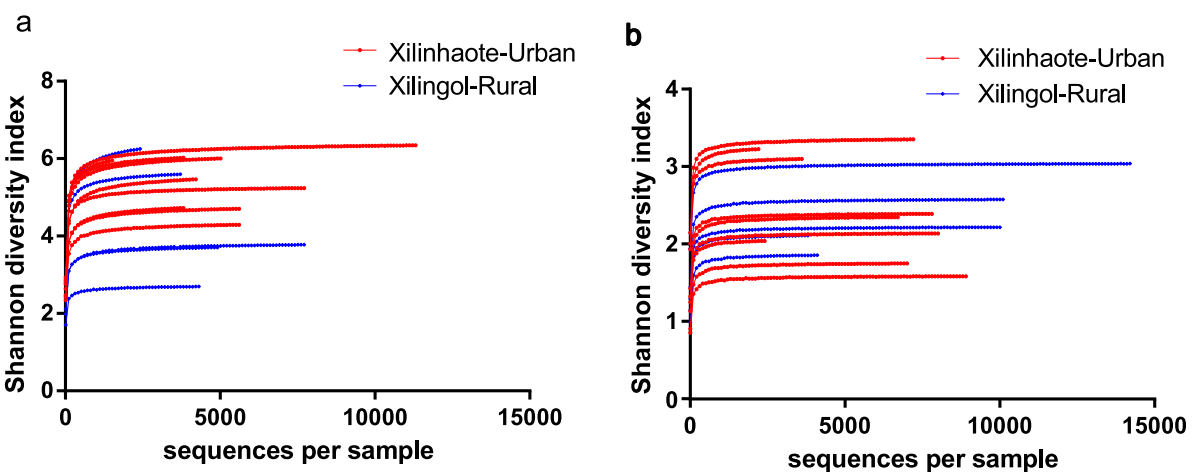

Fig. 2 Shannon diversity index of bacterial (a) and yeast (b) composition

of yeast species and LAB was also observed (Fig. 6). The abundance of the predominant bacterial species Lactobacillus helveticus (L. helveticus) was positively correlated with that of Dekkera anomala (D. anomala) and $P$. $B Z 159(p<0.01)$, and negatively correlated to that of $K$. unispora $(p<0.05)$. The abundance of the second most dominant species, $L$. lactis, was positively correlated with that of $K$. unispora $(p<0.01)$ and negatively correlated with that of $D$. anomala and uncultured Guehomyces (both $p<0.05$ ).

\section{Correlations among koumiss microbiota, organic acids, and taste}

A complex correlation between koumiss microbiota and organic acid accumulation was observed (Fig. 6). Lactic acid accumulation was positively correlated with the abundance of Lactococcus raffinolactis (L. raffinolactis), L. lactis, and $K$. unispora, and negatively correlated with that of Lactobacillus kefiranofaciens (L. kefiranofaciens), D. anomala, and uncultured Guehomyces. Interestingly, the abundance of $L$. raffinolactis and L. lactis was positively correlated with acetic acid accumulation. The abundance of L. kefiranofaciens and M. caribbica was positively correlated with citric acid accumulation, and negatively correlated with tartaric and malic acid accumulation. The abundance of $L$. kefiranofaciens and unculturedGuehomyces was positively correlated with that of succinic acid, whereas L. lactis abundance had a negative correlation.

In the grouping study, Xilingol-rural samples exhibited stronger sourness $(p=0.06)$ and aftertaste-A (astringent aftertaste, $p=0.04$ ) than Xilinhaote-urban samples (Figure S1), but there were no differences in any other taste parameter.

Sourness, astringency and aftertaste-A, bitterness and aftertaste-B, and richness clustered together. Moreover, microbes making a positive contribution to sournessrelated tastes, including L. helveticus, L. kefiranofaciens, D. anomala, P. BZ159, uncultured Guehomyces, were negatively correlated with sweetness, umami and saltness.

Saltiness, umami, and sweetness were clustered together, and were positively correlated with $L$. lactis, $L$. raffinolactis, and $K$. unispora; these species were

Table 1 Average relative abundance of bacteria in different taxa

\begin{tabular}{|c|c|c|c|c|c|}
\hline Phylum & $\begin{array}{l}\text { average abundance } \\
(\%) \pm \mathrm{SE}\end{array}$ & Genus & $\begin{array}{l}\text { average abundance } \\
(\%) \pm \mathrm{SE}\end{array}$ & Species & $\begin{array}{l}\text { average abundance } \\
(\%) \pm \mathrm{SE}\end{array}$ \\
\hline \multirow[t]{5}{*}{ Firmicutes } & \multirow[t]{5}{*}{$86.4 \pm 10.8$} & \multirow[t]{3}{*}{ Lactobacillus } & \multirow[t]{3}{*}{$69.5 \pm 24.6$} & Lactobacillus helveticus & $53.3 \pm 27.5$ \\
\hline & & & & Lactobacillus kefiranofaciens & $13.4 \pm 14.6$ \\
\hline & & & & Lactobacillus kefiri & $0.8 \pm 1.9$ \\
\hline & & \multirow[t]{2}{*}{ Lactococcus } & \multirow[t]{2}{*}{$15.6 \pm 19.2$} & Lactococcus lactis & $12.8 \pm 15.1$ \\
\hline & & & & Lactococcus raffinolactis & $2.3 \pm 7.9$ \\
\hline \multirow[t]{4}{*}{ Proteobacteria } & \multirow[t]{4}{*}{$13.6 \pm 10.7$} & Pseudomonas & $2.3 \pm 5.2$ & - & - \\
\hline & & Acetobacter & $1.5 \pm 2.12$ & - & - \\
\hline & & Enterobacter & $1.4 \pm 1.2$ & - & - \\
\hline & & Citrobacter & $2.5 \pm 6.4$ & Citrobacter freundii & $1.1 \pm 3$ \\
\hline unclassified & 0 & unclassified & $3.6 \pm 3.6$ & unclassified & $11.5 \pm 7.3$ \\
\hline
\end{tabular}


Table 2 Average relative abundance of yeast in different taxa

\begin{tabular}{llllll}
\hline Phylum & $\begin{array}{l}\text { average abundance } \\
(\%) \pm \text { SE }\end{array}$ & Genus & $\begin{array}{l}\text { average abundance } \\
(\%) \pm \text { SE }\end{array}$ & Species & $\begin{array}{l}\text { average abundance } \\
(\%) \pm \text { SE }\end{array}$ \\
\hline Ascomycota & $97.5 \pm 1.3$ & Dekkera & $64.2 \pm 19.8$ & Dekkera anomala & $64.2 \pm 19.8$ \\
& & Kazachstania & $14.2 \pm 18.7$ & Kazachstania unispora & $14.1 \pm 18.6$ \\
& Meyerozyma & $3 \pm 4.8$ & Meyerozyma caribbica & $3 \pm 3.9$ \\
& & Pichia & $3.7 \pm 1.8$ & Pichia sp.BZ159 & $3 \pm 1.8$ \\
& & Kluyveromyces & $3.3 \pm 4.2$ & Kluyveromyces marxianus & $2.8 \pm 4.9$ \\
Basidiomycota & $2.4 \pm 1.3$ & unclassified & & unculturedGuehomyces & $2 \pm 1.3$ \\
unclassified & $0.1 \pm 0.1$ & unclassified & $10.9 \pm 2.1$ & unclassified & $9.3 \pm 1.3$ \\
\hline
\end{tabular}

These tables didn't show the species relative abundance was lower than $1 \%$

negatively correlated with sourness-related tastes (Fig. 7). Only Kluyveromyces marxianus ( $K$. marxianus) was positively correlated with sweetness $(p<0.01)$.

Redundancy analysis (RDA) was performed to identify the species in koumiss associated with the various types of tastes and organic acids (Fig. 8). L. helveticus and D. anomala were strongly associated with sourness, astringency, bitterness, and aftertaste. L. lactis and K. unispora were strongly associated with umami and lactic and acetic acids. $K$. marxianus was associated with malic, tartaric, and oxalic acids. L. kefiranofaciens was associated with citric acid.

\section{Discussion}

\section{Bacterial and yeast diversity}

Koumiss taste can be classified into three types according to the lactic acid content: strong (0.91-1.08\%), moderate (0.73-0.90\%), and weak $(0.54-0.72 \%)$ [22]. According to this classification, the koumiss in the present study was classified as a weak form from fermented mare's milk.

Many studies on koumiss bacterial or yeast diversity used culture- or molecular biology-based methods; however, results varied significantly due to differences in the analysis techniques applied, research approaches, and geographic regions [23-26]. In the current study, we applied long-read SMRT sequencing technology (Pac Bio) with high-resolution phylogenetic microbial community profiling [27] to identify a novel dominant bacterial species, Citrobacter freundii that had not been reported previously; the dominant yeast species were $M$. caribbica and uncultured Guehomyces. One observation in our study that was inconsistent with previous research was that the abundance of Enterobacter genus was $<1 \%$; this may be because the samples were freshly fermented koumiss, whereas Enterobacter was found to be enriched during later fermentation and is related to flavor ripening [28]. In our study, the abundance of Acetobacter genus was lower $(1.5 \pm 2.13 \%)$, and mainly consisted of Acetobacter malorum, Acetobacter pasteurianus, and Acetobacter orientalis. The heterofermentative species included a small amount of Lactobacillus kefiri $(0.82 \pm$ $1.86 \%)$ and Leuconostoc mesenteroides (0.53 $\pm 1.45 \%)$.

Regarding most diverse bacterial composition between two groups, the mesophilic bacteria L. lactis was absent from Xilingol-rural koumiss samples, there may be a competition relationship between $L$. lactis and $L$. helveticus, because $L$. helveticus utilizes galactose moieties and glucose, whereas L. lactis only utilizes the latter [29]. Regarding interactions among bacterial species, in a previous study, mixed cultures of Lactococcus lactis ssp. lactis and $L$. raffinolactis stimulated more acid production
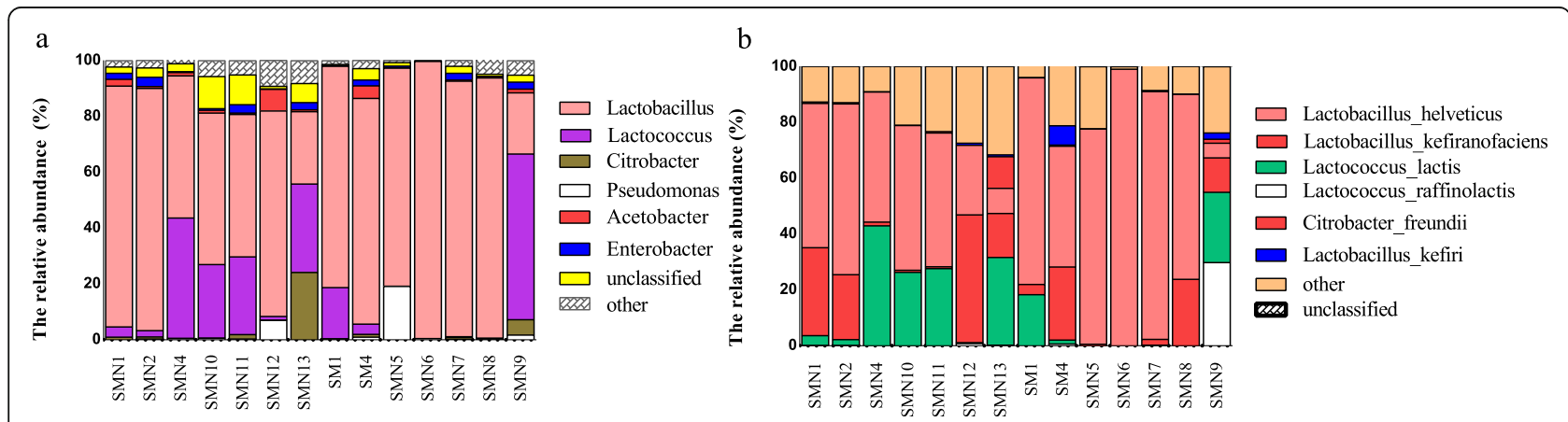

Fig. 3 The relative abundance of bacterial genus (a) and species (b) 

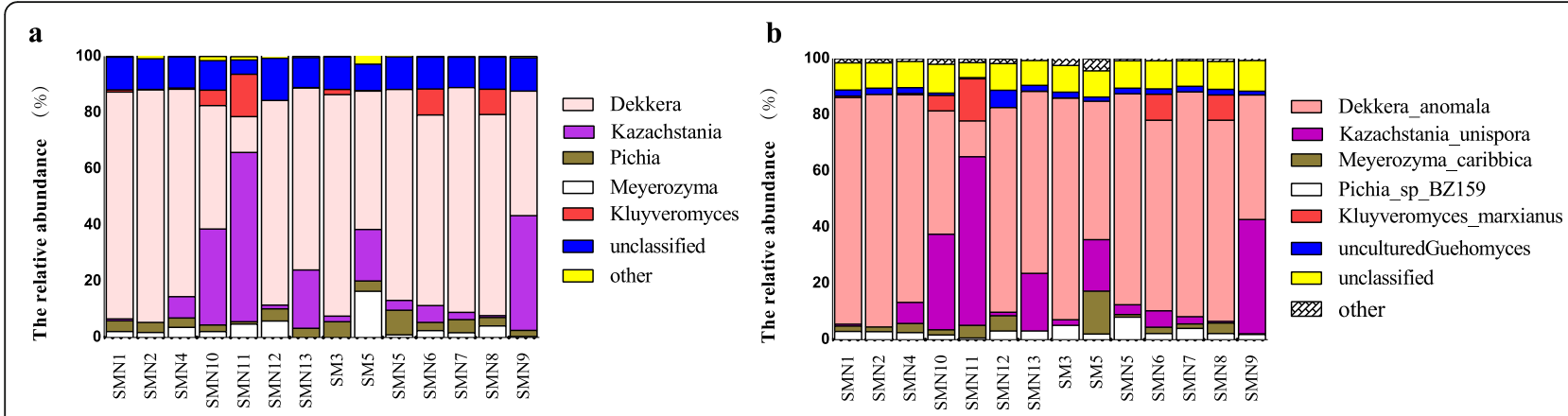

Fig. 4 The relative abundance of fungal genus (a) and species (b)

during skim milk fermentation [30]. One possible reason for this is that $L$. raffinolactis strains are able to ferment $\alpha$-galactosides [31], which are not utilized by L. lactis strains. However, in the current study, although L. lactis and $L$. raffinolactis showed a trend toward a positive correlation in their abundances, it was not statistically significant. In contrast, the abundances of L. kefiranofaciens and $L$. raffinolactis were positively correlated. $L$. kefiranofaciens is rarely isolated from koumiss [32] but is a key LAB species in kefir grain ecosystems [33]. Citrobacter freundii (C. freundii) is a common component of the gut microbiome of healthy humans, and of soil, and is a widely distributed opportunistic pathogen [34]. C. freundii was found in one sample at an abundance of $11.37 \%$ but was present in very small amounts in other samples; thus, the high-abundance sample may have been due to contamination.

Yeasts producing koumiss (alcoholic) can ferment lactose or galactose. In the current study, the lactosefermenting yeasts were $D$. anomala and $K$. marxianus, while the galactose-fermenting yeasts included $K$. unispora and M. caribbica.

The predominant yeast species, $D$. anomala, belongs to the genera Dekkera (Brettanomyces), which is known for its ability to spoil alcoholic beverages by producing acetic acid and unpleasant flavors and odors [35, 36]. D. anomala is the teleomorph of Brettanomyces anomalus; it differs morphologically and physiologically from the other species in the genus Dekkera in terms of the formation of blastese and the ability to ferment lactose [37]. D. anomala IGC 5153 exhibited limited ability to use weak acids as its only source of carbon and energy. The acetate carrier was not only inducible, but also subject to glucose repression, similar to the carriers identified in acetic acid-grown cells of yeasts such as $S$. cerevisiae. D. anomala grew in acetic acid-containing medium with a relatively high total acid content, and over a broad $\mathrm{pH}$ range including $\mathrm{pH} 3.5$. D. anomala isolates were obtained from Inner Mongolia Koumiss samples and shown by polymerase chain reaction denaturing gradient gel electrophoresis (PCR-DGGE) to be present in an amount of 7.29\% [9]; this differs from our sequencing results, which showed amounts of $13-83 \%$. In other milk products, $D$. anomala was isolated from kefir, koumiss, and Shubat [25, 32, 38]. Feta cheese made from pasteurized ewe's milk contains $D$. anomala. Because wood is an ecological niche for this strongly fermented species, its presence is likely attributable to the wooden tables used for dry salting the cheese blocks [39]. In the current study, the two samples with the lowest abundance of $D$. anomala were fermented in crock using a traditional method. This suggests that non-wood
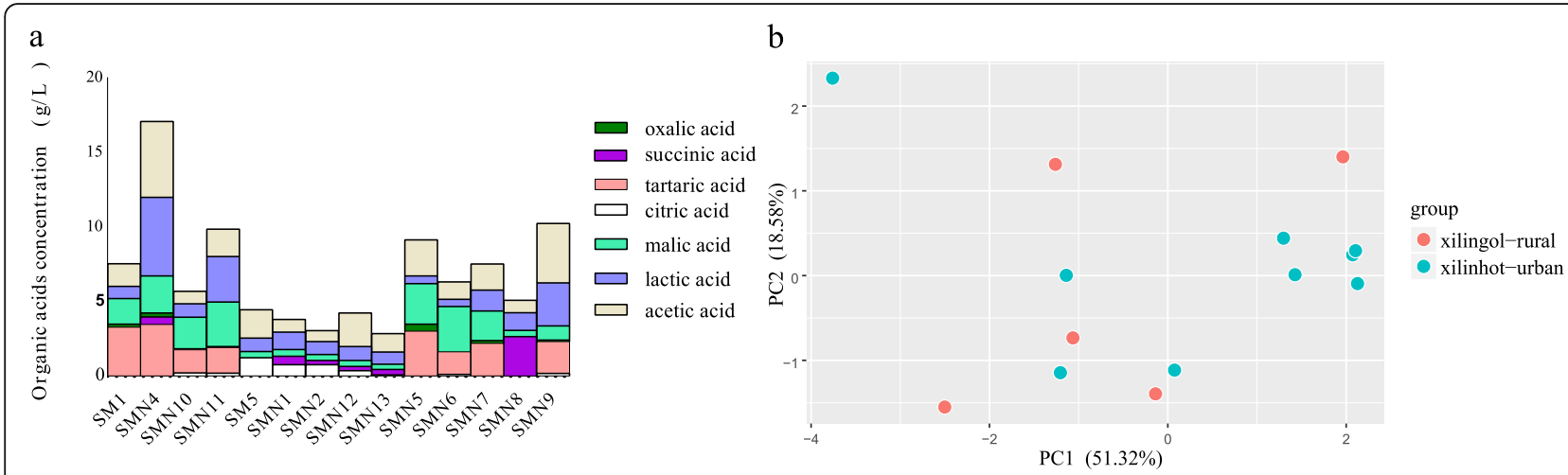

Fig. 5 Koumiss organic acids profiling and PCA analysis 


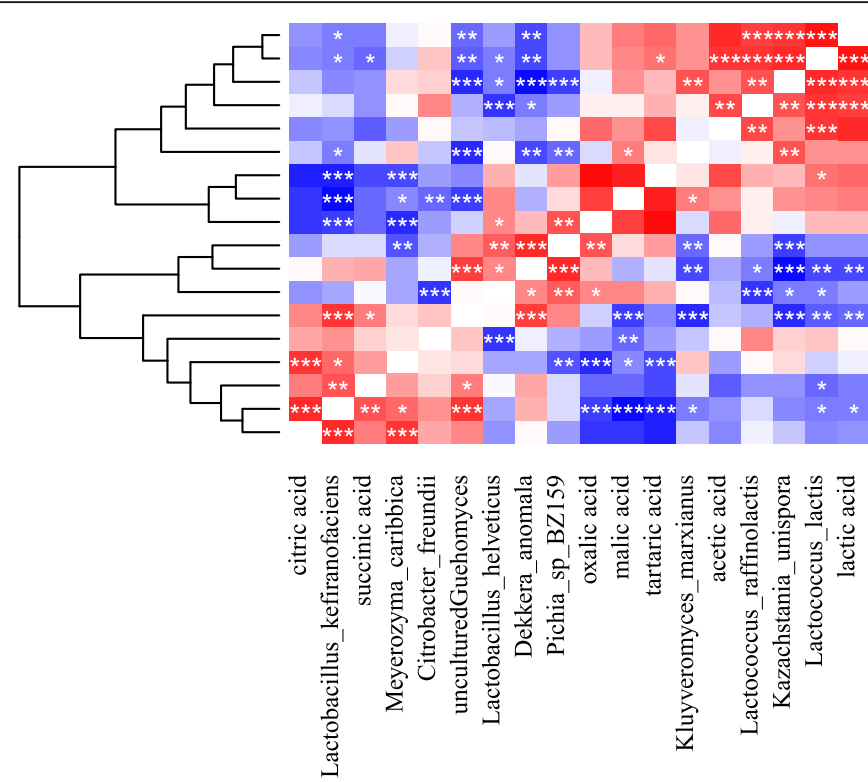

lactic acid

Lactococcus lactis

Kazachstania unispora

Lactococcus_raffinolactis

acetic acid

Kluyveromyces marxianus

tartaric acid

malic acid

oxalic acid

Pichia sp BZ159

Dekkera anomala

Lactobacillus_helveticus

unculturedGuehomyces

Citrobacter freundii

Meyerozyma caribbica

succinic acid

Lactobacillus_kefiranofaciens

citric acid

Fig. 6 The Correlation of Koumiss Microbiota and Organic Acids. There are no shown the relationship between the organic acids. In the figure "**" represents $p<0.05$, "***" represents $p<0.01$, ${ }^{\prime \prime * * * " ~ r e p r e s e n t s ~} p<0.001$

containers and stirrers could be used to restrain the overgrowth of this species. In our koumiss samples, $D$. anomala may have partially contributed to the production of acetic acid, but its correlation with the acetic acid content was negative and nonsignificant (Fig. 6). This may be because it can transport acetic acid into cells as a carbon source to produce $\mathrm{CO}_{2}$; this is known as the Crabtree effect and underlies the "make-accumulate- consume" life strategy of organisms such as S. cerevisiae $[40,41]$. It is a strongly fermented species that may bloom at the beginning stage of fermentation.

The second most common yeast species was $K$. unisporus. A previous study found that its dominance increased at higher altitudes [42], but in koumiss samples from the Xilingol prairie, where latitude does not vary greatly, the abundance varied widely from 0.03 to $60 \%$.

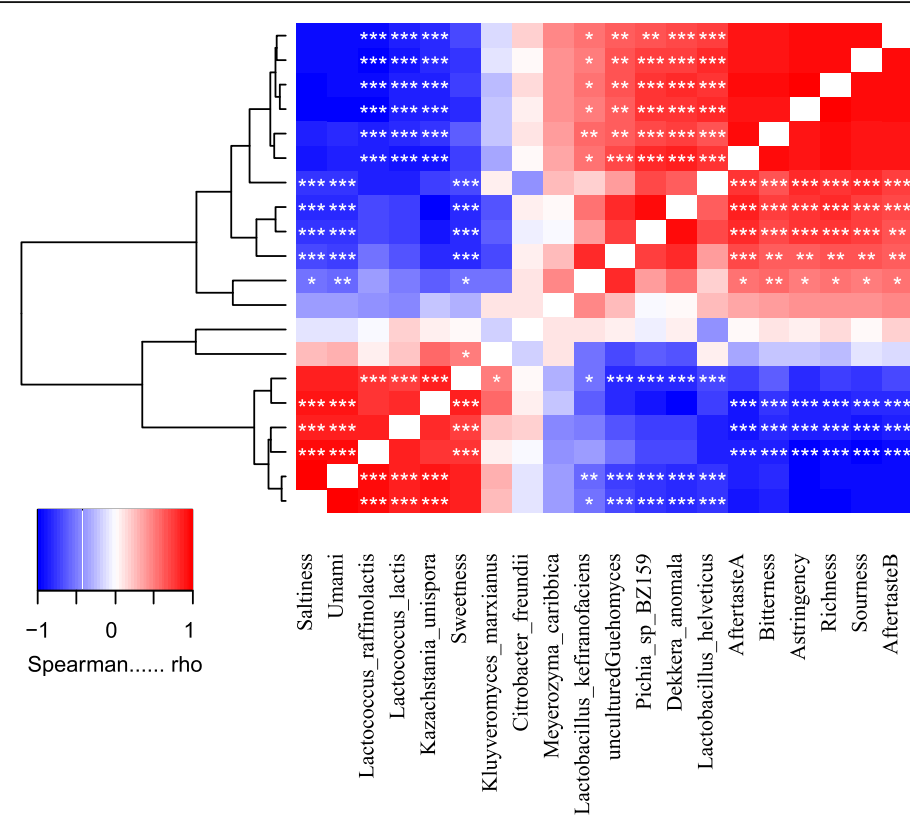

AftertasteB

Sourness

Richness

Astringency

Bitterness

AftertasteA

Lactobacillus_helveticus

Dekkera_anomala

Pichia sp BZ159

unculturedGuehomyces

Lactobacillus_kefiranofaciens

Meyerozyma_caribbica

Citrobacter_freundii

Kluyveromyces_marxianus

Sweetness

Kazachstania unispora

Lactococcus lactis

Lactococcus_raffinolactis

Umami

Saltiness

Fig. 7 The correlation of koumiss microbiota and the taste. There are no shown the relationships between the species each other and taste in the figure. In the figure "**represents $p<0.05$, "**" represents $p<0.01$, "***" represents $p<0.001$ 


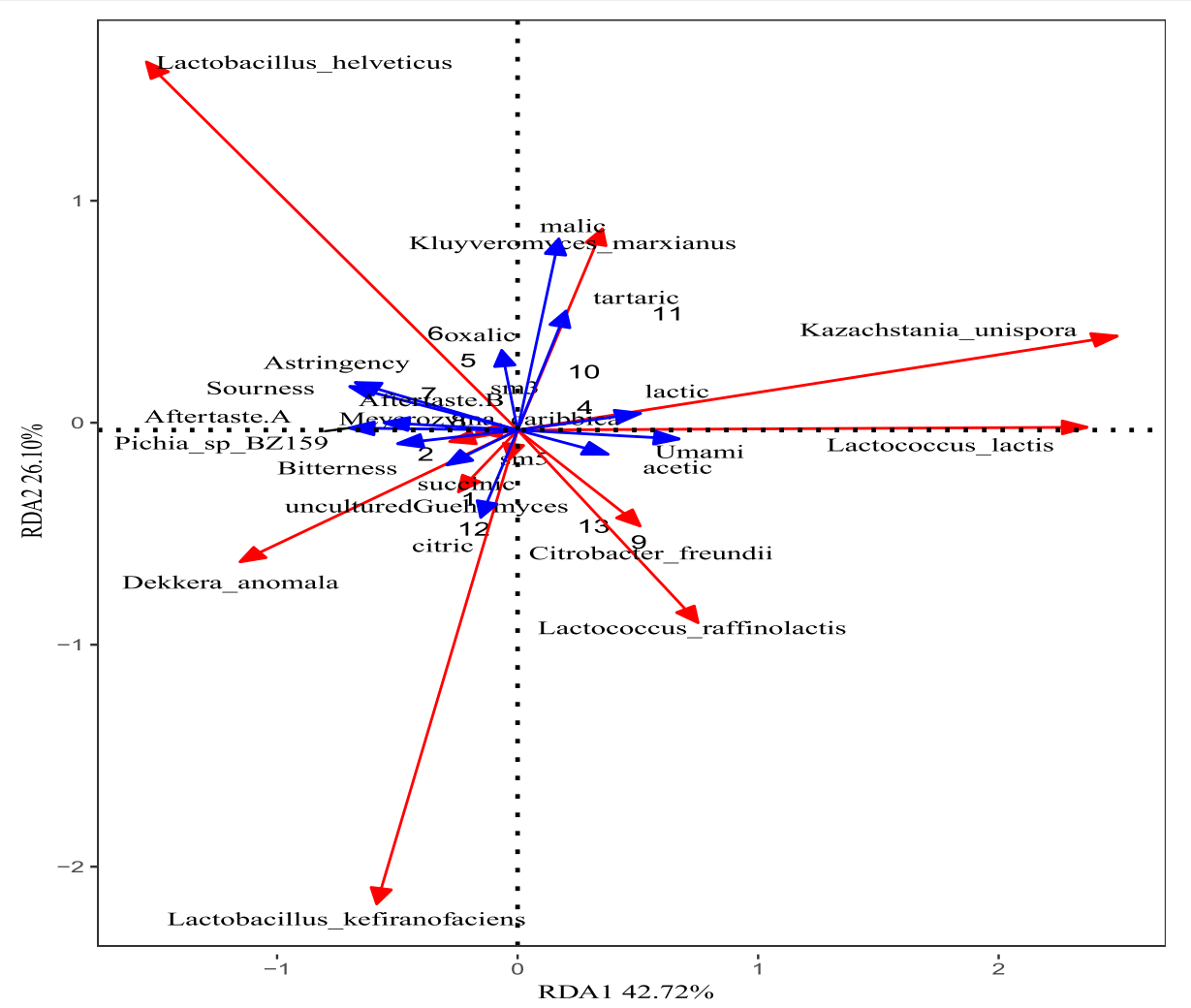

Fig. 8 Redundancy analysis of koumiss Microbiota on organic acids and taste. The numbers stands for samples, exception sample 'sm3'and'sm5'. The blue arrows represent the response variables (organic acids and taste), and the red arrows represent the species variables

K. unisporus has been found in various dairy products. It is a galactose-fermenting yeast species and the principal microorganism responsible for alcoholic fermentation, but is a slow producer of ethanol and performs a clean fermentation in milk and whey. Thiamine is the only vitamin required exogenously for the growth of $K$. unisporus; therefore, thiamine may be a key factor determining its prevalence [43]. These samples are weakly fermented koumiss, there is a limited amount of galactose in the system, which may also be another factor.

The yeast Shannon diversity index of Xilinhaote-urban samples was significantly higher than that of Xilingolrural samples, mainly because of the absence of $K$. marxianus in most Xilingol-rural samples. K. marxianus utilizes lactose to excrete some glucose and galactose into milk and weakly metabolizes citrate and succinic acids to produce ethanol, glycerol, acetic acid, and propionic acid [10]. K. marxianus is also emerging as a new platform for the production of flavor and fragrance compounds [44]; it is used for the production of phenylethyl alcohol, responsible for the aroma of roses in cheese whey [45].

M. caribbica, P. BZ159, and uncultured Guehomyces were detected in the koumiss samples, and their presence may be attributable to the non-starter yeast species.
The species within the genus Pichia are methylotrophic yeasts [46]. P. BZ 159 has two alcohol oxidase genes, aox $\mathrm{A}$ and $a o x \mathrm{~B}$, which can oxidize alcohols to aldehydes with concomitant production of hydrogen peroxide. Glucose strongly suppresses the expression of both genes [47].

\section{Koumiss organic acid profiling}

For the first time, we systematically identified the organic acids responsible for the sour taste of koumiss. The organic acid composition did not directly reflect the grouping of samples; in fact, it better-reflected the fermentation process. Most organic acids produced by microbes can be divided into two main groups depending on their metabolic origin and the main metabolite sequence of the aerobic organism: those associated with the tricarboxylic acid cycle (TCA) and glycolysis arising from the oxidation of glucose; and those using glucose to produce organic acids. Citric, lactic, and malic acids fall into the first group, whereas acetic acid should be considered a biotransformation of ethanol. Succinic acid is mostly produced using chemical methods. K. unisporus ferments certain monosaccharides to produce succinic acid and acetic acid during ethanol fermentation [48], where the lactic and acetic acid content is the 
main indicator of the fermentation dynamic. In the present study, the average acetic acid content was higher than the lactic acid content, which may be the result of weak fermentation; as the fermentation proceeds, lactic acid may become dominant over acetic acid. In the bacterial community, most bacteria are homofermentative species and the less-abundant heterofermentative species, including L. kefiri and Leuconostoc mesenteroides, produce acetic acid in koumiss. The trace amounts of acetic acid may by generated from ethanol by acetic acid bacteria [49]. More importantly, few LAB species are able to co-metabolize citrate with fermentable sugars to produce acetic acid. Specifically, variants of $L$. lactis (i.e., L. lactis subsp.lactis biovar diacetylactis) are capable of citrate utilization because they possess a plasmidencoded citrate transporter gene [50]. Our samples may have contained variants of $L$. lactis. In the yeast community, acetic acid-producing species include $D$. anomala and $K$. unisporus.

There were significant lower content of citric acid in Xilingol-rural than Xilinhaote-urban groups. Citric acid is a common constituent of milk; its abundance in mare's milk is $<2.3 \mathrm{~g} / \mathrm{kg}$. Moreover, it is a substrate for certain $\mathrm{LAB}$, which use it to form aromatic substances such as acetoin and diacetyl $[51,52]$. In our study, the more sour Xilingol-rural samples had lower citric acid content, which was consistent with the result that its content decreased with fermentation. During fermentation, the citric acid content did not remain steady. First, microbes use glucose to produce citric aacid via the TCA cycle, and then to form aromatic precursors. In addition, citric, malic, and succinic acids are components of the TCA, which together contributed to sourness and bitterness. There are subtle differences in taste: malic acid has a tart, smooth, and long-lasting flavor [48], whereas citric acid has a sour and bitter aftertaste that lasts only for a short time. Succinic acid has an acidic and salty/bitter taste and is savory in cheese [53].

Succinic acid is a good indicator of yeast inoculation status. It is the main organic acid produced by yeast and is formed in the glyoxylate cycle via oxidation of isocitrate, as well as in the reductive citric acid cycle [54]. In the current study, succinic acid accumulation correlated with the abundance of uncultured Guehomyces and $L$. kefiranofaciens.

\section{Koumiss microbiota: association with taste}

In the past, more attention was paid to bacterial as opposed to yeast species, even though both bacteria and yeast contribute to unique koumiss fermentation. The presence of yeast in dairy products contributes to flavor formation via the synthesis of a variety of chemical compounds [55]. The koumiss starter culture only containing a few strains of microbes [56] may loss many benefits of koumiss consumption. In tradition, a small aliquot of koumiss from end product is retained for use as starters for the next batch, this method was out of accurate control of fermentation. Redundancy and correlation analysis suggest that those species are associated with tastes and organic acids in koumiss. To control excessive sourness, astringency, and bitterness during koumiss production, our data suggest that the amounts of the post-acidifying strains $L$. helveticus and $D$. anomala should be reduced, or those of L. lactis and K. unispora increased, in the koumiss starter culture.

Studies of the interaction between bacteria and yeast in fermented foods yield inconsistent results due to differences in strains, substrates and food matrices $[26,55$, $57,58]$. During the fermentation of food products, five types of interactions occur between, and may play a role in the consortia of, microbes [59]. However, the putative correlations identified could not be distinguished in terms of whether they were direct or indirect, nor could directionality be established [60]. A study of the interaction between $L$. lactis and yeast found that $L$. lactis produced acetic acid when co-cultured with some yeasts; moreover, the growth of L. lactis was enhanced in most co-cultures in UHT milk [61]. The present study observed a potential symbiotic relationship between bacteria and yeast; however, the mechanism underlying this putative relationship is unclear so further research is necessary.

\section{Conclusions}

The dominant microbes in the weak form of koumiss derived from fermented mare's milk (in the Xilingol region) analyzed in this study includes $L$. helveticus, $L$. kefiranofaciens, L. lactis, L. raffinolactis, D. anomala, $K$. unispora, M. caribbica, P. BZ159, K. marxianus and uncultured Guehomyces. The abundance of L. lactis significantly lower in Xilingol-rural samples than Xilinhaoteurban samples. Lactic, acetic, tartaric, and malic acids were the main organic acids that accumulated during koumiss fermentation. LAB species were mostly responsible for the accumulation of those organic acids, although K. unispora, D. anomala, and M. caribbica may also have contributed. The RDA showed that L. helveticus and D. anomala are associated with sourness, astringency, bitterness, and aftertaste, whereas L. lactis and $K$. unispora are associated with umami. The interaction between bacteria and yeast could be demonstrated more convincingly an orthogonal single-strain fermentation experiment combined with a meta-transcriptome study. Our study provides reference values to improve understanding of the interaction between bacteria and yeast in koumiss. These results could inform the selection of multiple-strain cultures for use as bacteria and yeast mixed starter cultures. 


\section{Methods}

\section{Sample collection}

Fourteen fresh naturally fermented koumiss samples were collected from the Xilingol region of Inner Mongolia and stored at $-80^{\circ} \mathrm{C}$ until analysis. The samples were classified into two groups according to the collection site. "Xilinhaote-urban" samples were collected around Xilinhaote city, where koumiss is produced at the ranch scale (including SMN1, SMN2, SMN4, SMN11, SMN12, SMN13, SM3 alternative to SM1, SM5 alternative to SM4), whereas "Xilingol-rural" samples were collected from herdsmen located $100-150 \mathrm{~km}$ from Xilinhaote city (including SMN5, SMN6, SMN7, SMN8, and SMN9). We evaluated the koumiss quality and sensory by two senior dairy researchers in situ when samples were collected.

\section{DNA extraction and PCR amplification}

Genomic DNA was extracted using an Omega DNA Soil Kit (Omega Bio-Tek, Inc., Norcross, GA, USA) following the manufacturer's instructions. The quality of the extracted DNA was verified using 1.0\% agarose gel electrophoresis and a NanoDrop ND-1000 spectrophotometer (Thermo Fisher Scientific, Waltham, MA, USA). All extracted DNA samples were stored at $-20^{\circ} \mathrm{C}$ until analysis.The full-length sequences of $16 \mathrm{~S}$ rRNA from genomic DNA were amplified using barcoded universal primers $27 \mathrm{~F}$ and $1492 \mathrm{R}$. Despite the wide use of ITS rRNA as a fungal DNA barcode, its ability to resolve relationships at higher taxonomic levels is inferior to that of many protein-coding genes. Therefore, we combined ITS with the large rRNA subunit ( $28 \mathrm{~S}$ rRNA) to differentiate target organisms from close phylogenetic neighbors $[62,63]$. The $28 \mathrm{~S}$ rRNA and ITS genes of yeast were amplified using ITS/28S barcoded primers (forward, 5' -TCCGTAGGTGAACCTGCGG-3'; reverse 5' TCCTGAGGGAAACTTCG-3'). The PCR program was as follows: $95^{\circ} \mathrm{C}$ for $2 \mathrm{~min}, 98^{\circ} \mathrm{C}$ for $20 \mathrm{~s}, 60^{\circ} \mathrm{C}$ for $15 \mathrm{~s}$, $72{ }^{\circ} \mathrm{C}$ for $45 \mathrm{~s}$, and a final extension of $72{ }^{\circ} \mathrm{C}$ for $90 \mathrm{~s}$. The PCR was performed over 28 cycles for bacteria and 30 cycles for yeast. HiFi HotStart ReadyMix PCR Kit (Kapa Biosystems, Wilmington, MA, USA) was used and reactions were supplemented with 5\% DMSO to improve the amplification of yeast DNA $[64,65]$. The amplification library was built and used for single-molecule real-time (SMRT) sequencing (Pac Bio, Menlo Park, CA, USA).

\section{Identification of organic acids by HPLC}

The organic acid compounds in koumiss were quantified using a high performance liquid chromatography (HPLC) system (Agilent 1100; Agilent, Santa Clara, CA, USA) with a $\mathrm{C}_{18} \mathrm{SB}-\mathrm{Aq}$ chromatographic column $(5 \mu \mathrm{m}$, $4.6 \mathrm{~mm} \times 250 \mathrm{~mm})$, solution volume ratio (PBS at a concentration of $10 \mathrm{mmol} / \mathrm{L}, \mathrm{pH} 2.0$ ) of 3:97, and UV detection wavelength of $210 \mathrm{~nm}$ [66].

\section{Taste analysis by a taste-sensing system}

The koumiss samples were diluted 1:1 with doubledistilled water and centrifuged at $1700 \times g$ at $4{ }^{\circ} \mathrm{C}$ for 10 min. The supernatants were analyzed using the SA402B taste-sensing system (Intelligent Sensor Technology, Inc., Kanagawa, Japan). A random sample placed in the first position was used as the control.

\section{Statistical analysis}

The data are presented as means \pm standard error (SE). Statistical analyses were performed using $\mathrm{R}$ software (version 3.4.4; R Development Core Team, Vienna, Austria). Statistical differences between two groups were assessed using the Wilcoxon rank sum test. Differences were judged to be statistically significant when $p<0.05$. Spearman's rank correlation was used to determine the relationships among species, flavor, and organic acids. Graphs were generated using the 'ggplot2' R package (Hadley Wickham, V2.2.1) and GraphPad Prism software (version 7.0; GraphPad Software, Inc., San Diego, CA, USA).

\section{Supplementary information}

Supplementary information accompanies this paper at https://doi.org/10. 1186/s12866-020-01773-Z.

Additional file 1: Figure S1. Radar curves for koumiss taste data. The red refer to Xilinhot-Urban samples, and blue refer to Xilingol-Rural samples.

\section{Abbreviations}

LAB: lactic acid bacteria; PC: Principal component; SMRT: Single Molecule Real-Time; TCA: Tricarboxylic acid cycle; RDA: Redundancy analysis;

UHT: Ultra-high temperature instantaneous sterilization

\section{Acknowledgements}

Thank Mark Goettel for grammar check on the first draft of the paper.

Authors' contributions

Conceived and designed the experiments: WJL ZHS HLTHBS BLGMH. Performed the experiments: HT HMM. Analyzed the data: QCH WCL HLTHBS. Contributed reagents/materials/primer design/analysis tools: HT HMM WCL QCH HYX. Wrote the paper: HT. All authors read and approved the final manuscript.

\section{Funding}

This research was supported by Science and Technology Project of Inner Mongolia Autonomous Region, China (No. 201802097). The funders played no role in the design of the study, analysis, and interpretation of data or in writing the manuscript.

\section{Availability of data and materials}

The nucleotide sequence data reported in this study have been deposited in the MG-RAST database (accession No.mgp91551). Other data are available from the corresponding author on reasonable request.

Ethics approval and consent to participate Not applicable. 


\section{Consent for publication}

Not applicable.

\section{Competing interests}

The authors declare that they have no competing interests.

\section{Author details}

${ }^{1}$ Key Laboratory of Dairy Biotechnology and Engineering, Ministry of Education, Inner Mongolia Agricultural University, Hohhot 010018, People's Republic of China. ${ }^{2}$ Key Laboratory of Dairy Products Processing, Ministry of Agriculture, Inner Mongolia Agricultural University, Hohhot 010018, People's Republic of China. ${ }^{3}$ Inner Mongolia International Mongolian Hospital, Hohhot 010018, People's Republic of China.

\section{Received: 4 November 2019 Accepted: 29 March 2020}

\section{Published online: 10 April 2020}

\section{References}

1. Akuzawa R, Surono IS. Asian fermented milks. In: Encyclopedia of Dairy Science. Edited by R A, T M, IS S, vol. 2. San Diego: Academic; 2011. p. $507-11 .$.

2. Zhang WZ. Fermentation and Koumiss. In: Handbook of Animal-Based Fermented Food and Beverage Technology; 2012. p. 165-72.

3. Bilige M, Ri-na W, Zhi-hong S, Zhang H. Isolation and identification of Lactobacillus from koumiss collected in Inner Mongolia and People's republic of Mongolia. Chin Dairy Indust. 2004;32(11):6-11.

4. Wszolek M, Kupiec-Teahan B. Production of kefir, Koumiss and Other Related Products; 2006. p. 174-216.

5. Wu R, Wang W, Yu D, Zhang W, Li Y, Sun Z, Wu J, Meng H, Zhang H. Proteomics analysis of Lactobacillus casei Zhang, a new probiotic bacterium isolated from traditional home-made koumiss in Inner Mongolia of China. Mol Cell Proteomics. 2009;8(10):2321-38.

6. Ringø E, Andersen R, Sperstad S, Zhou Z, Ren P, Breines EM, Hareide E, Yttergård GJ, Opsal K, Johansen HM, et al. Bacterial Community of Koumiss from Mongolia investigated by culture and culture-independent methods. Food Biotechnol. 2014:28(4):333-53.

7. Danova S, Petrov K, Pavlov P, Petrova P. Isolation and characterization of Lactobacillus strains involved in koumiss fermentation. Int J Dairy Technol. 2005;58:100-5

8. Zhong Z, Hou Q, Kwok L, Yu Z, Zheng Y, Sun Z, Menghe B, Zhang H. Bacterial microbiota compositions of naturally fermented milk are shaped by both geographic origin and sample type. J Dairy Sci. 2016;99(10):7832-41.

9. $\mathrm{Mu} Z$, Yang $X$, Yuan H. Detection and identification of wild yeast in koumiss. Food Microbiol. 2012;31(2):301-8.

10. Roostita R, Fleet GH. Growth of yeasts in milk and associated changes to milk composition. Int J Food Microbiol. 1996;31:205-19.

11. Picon A, Lopez-Perez O, Torres E, Garde S, Nunez M. Contribution of autochthonous lactic acid bacteria to the typical flavour of raw goat milk cheeses. Int J Food Microbiol. 2019;299:8-22.

12. Dertli $E$, Çon AH. Microbial diversity of traditional kefir grains and their role on kefir aroma. LWT Food Sci Technol. 2017;85:151-7.

13. Liu W, Zheng Y, Kwok L-Y, Sun Z, Zhang J, Guo Z, Hou Q, Menhe B, Zhang $\mathrm{H}$. High-throughput sequencing for the detection of the bacterial and fungal diversity in Mongolian naturally fermented cow's milk in Russia. BMC Microbiol. 2015;15(1):45.

14. Urbienè $\mathrm{S}$, Leskauskaitè $\mathrm{D}$. Formation of some organic acids during fermentation of milk. Polish J Food Nutr Sci. 2006;15(3):277-81.

15. Kilcawley KN, Faulkner H, Clarke HJ, O'Sullivan MG, Kerry JP. Factors influencing the flavour of bovine milk and cheese from grass based versus non-grass based milk production systems. Foods. 2018;7(3):37.

16. Bovolenta S, Romanzin A, Corazzin M, Spanghero M, Aprea E, Gasperi F, Piasentier E. Volatile compounds and sensory properties of Montasio cheese made from the milk of Simmental cows grazing on alpine pastures. J Dairy Sci. 2014;97(12):7373-85.

17. Kobayashi Y, Habara M, Ikezazki H, Chen R, Naito Y, Toko K. Advanced taste sensors based on artificial lipids with global selectivity to basic taste qualities and high correlation to sensory scores. Sensors (Basel). 2010;10(4): 3411-43.
18. Tian $\mathrm{H}$, Shen $\mathrm{Y}, \mathrm{Yu} \mathrm{H}, \mathrm{He}$ Y, Chen C. Effects of 4 probiotic strains in Coculture with traditional starters on the flavor profile of yogurt. J Food Sci. 2017;82(7):1693-701.

19. Mizota Y, Matsui H, Ikeda M, Ichihashi N, Iwatsuki K, Toko K. Flavor evaluation using taste sensor for UHT processed milk stored in cartons having different light permeabilities. Milchwissenschaft. 2009;64(2):143-6.

20. Cai W, Tang F, Zhao X, Guo Z, Zhang Z, Dong Y, Shan C. Different lactic acid bacteria strains affecting the flavor profile of fermented jujube juice. J Food Process Preserv. 2019;43(9):e14095.

21. Muyanja CMBK, Narvhus JA, Langsrud T. Organic acids and volatile organic compounds produced during traditional and starter culture fermentation of Bushera, a Ugandan fermented cereal beverage. Food Biotechnol. 2012:26:1-28.

22. Robinson RK, Tamime AY, Wszolek M. Microbiology of fermented milks. In: Robinson RK, editor. Dairy Microbiology Handbook: The Microbiology of Milk and Milk Product. 3rd ed: Wiley. Hobeken, NJ; 2002:367-430.

23. Sun Z, Liu W, Zhang J, Yu J, Zhang W, Cai C, Menghe B, Sun T, Zhang H, Identification and characterization of the dominant lactobacilli isolated from koumiss in China. J Gen Appl Microbiol. 2010;56:257-65.

24. Hao Y, Zhao L, Zhang H, Zhai Z, Huang Y, Liu X, Zhang L. Identification of the bacterial biodiversity in koumiss by denaturing gradient gel electrophoresis and species-specific polymerase chain reaction. J Dairy Sci. 2010;93(5):1926-33.

25. Baubekova A, Akhmetsadykova S, Konuspayeva G, Akhmetsadykov N, Faye B, Loiseau G. Biodiversity study of the yeast in fresh and fermented camel and mare's milk by denaturing dradient gel electrophoresis. J Camel Pract Res. 2015;22(1):91-5.

26. Houngbedji M, Johansen P, Padonou SW, Akissoe N, Arneborg N, Nielsen $D S$, Hounhouigan DJ, Jespersen L. Occurrence of lactic acid bacteria and yeasts at species and strain level during spontaneous fermentation of mawe, a cereal dough produced in West Africa. Food Microbiol. 2018;76: $267-78$.

27. Singer E, Bushnell B, Coleman-Derr D, Bowman B, Bowers RM, Levy A, Gies EA, Cheng JF, Copeland A, Klenk HP, et al. High-resolution phylogenetic microbial community profiling. ISME J. 2016;10(8):2020-32.

28. Gesudu Q, Zheng Y, Xi X, Hou QC, Xu H, Huang W, Zhang H, Menghe B, Liu W. Investigating bacterial population structure and dynamics in traditional koumiss from Inner Mongolia using single molecule real-time sequencing. J Dairy Sci. 2016;99(10):7852-63.

29. Hickey MW, Hillier AJ, Jago GR. Transport and metabolism of lactose, glucose, and galactose in Homofermentative lactobacilli. Appl Environ Microbiol. 1985;51:825-31.

30. Kimoto-Nira H, Aoki R, Mizumachi K, Sasaki K, Naito H, Sawada T, Suzuki C. Interaction between Lactococcus lactis and Lactococcus raffinolactis during growth in milk: development of a new starter culture. J Dairy Sci. 2012;95(4): 2176-85.

31. Boucher I, Vadeboncoeur C, Moineau S. Characterization of genes involved in the metabolism of a-Galactosides by Lactococcus raffinolactis. Appl Environ Microbiol. 2003;69(7):4049-56

32. Watanabe K, Fujimoto J, Sasamoto M, Dugersuren J, Tumursuh T, Demberel S. Diversity of lactic acid bacteria and yeasts in Airag and Tarag, traditional fermented milk products of Mongolia. World J Microbiol Biotechnol. 2007; 24(8):1313-25.

33. Garofalo C, Osimani A, Milanovic V, Aquilanti L, De Filippis F, Stellato G, Di Mauro S, Turchetti B, Buzzini P, Ercolini D, et al. Bacteria and yeast microbiota in milk kefir grains from different Italian regions. Food Microbiol. 2015:49:123-33.

34. Wang JT, Chang SC, Chen YC, Luh KT. Comparison of antimicrobial susceptibility of Citrobacter freundii isolates in two different time periods. J Microbiol Immunol Infect. 2000;33(4):258-62.

35. Wedral $D$, Shewfelt R, Frank J. The challenge of Brettanomyces in wine. LWT Food Sci Technol. 2010;43(10):1474-9.

36. Gray SR, Rawsthorne H, Dirks B, Phister TG. Detection and enumeration of Dekkera anomala in beer, cola, and cider using real-time PCR. Lett Appl Microbiol. 2011;52(4):352-9.

37. Smith MT, Grinsven AMV. Dekkera anomala sp. nov., the teleomorph of Brettanomyces anomalus, recovered from spoiled soft drinks. Antonie van Leeuwenhoek. 1984;50:143-8.

38. Marsh AJ, O'Sullivan O, Hill C, Ross RP, Cotter PD. Sequencing-based analysis of the bacterial and fungal composition of kefir grains and milks from multiple sources. PLoS One. 2013;8(7):e69371. 
39. Fadda ME, Cosentino S, Deplano M, Palmas F. Yeast populations in Sardinian feta cheese. Int J Food Microbiol. 2001;69:153-6.

40. Marsit S, Dequin S. Diversity and adaptive evolution of Saccharomyces wine yeast: a review. FEMS Yeast Res. 2015;15(7):fov067.

41. Rozpedowska E, Hellborg L, Ishchuk OP, Orhan F, Galafassi S, Merico A, Woolfit M, Compagno C, Piskur J. Parallel evolution of the makeaccumulate-consume strategy in Saccharomyces and Dekkera yeasts. Nat Commun. 2011;2:302.

42. Montanari G, Zambonelli C, Grazia L, Kamesheva GK, Shigaeva MK Saccharomyces unisporus as the principal alcoholic fermentation microorganism of traditional koumiss. J Dairy Res. 1996;63:327-31.

43. Bhattacharya I, Yan S, Yadav JSS, Tyagi RD, Surampalli RY. Saccharomyces unisporus: Biotechnological Potential and Present Status. Comp Rev Food Sci Food Safety. 2013;12(4):353-63.

44. Morrissey JP, Etschmann MM, Schrader J, de Billerbeck GM. Cell factory applications of the yeast Kluyveromyces marxianus for the biotechnological production of natural flavour and fragrance molecules. Yeast. 2015;32(1):3-16.

45. Conde-Ba'ez L, Castro-Rosas J, Go'mez-Aldapa C. Evaluation of Waste of the Cheese Industry for the Production of Aroma of Roses (Phenylethyl Alcohol). Waste Biomass Valor. 2017;8:1343-50.

46. Woodward JR. Biochemistry and Applications of Alcohol Oxidase from Methylotrophic Yeasts Biotechnology. In: Autotrophic Microbiology and One-Carbon Melabolism: GACe: Kluwer Academic Publishers. Dordrechl; 1990:193-225.

47. Szamecz B, Urban G, Rubiera R, Kucsera J, Dorgai L. Identification of four alcohol oxidases from methylotrophic yeasts. Yeast. 2005;22(8):669-76.

48. Sahasrabudhe NA, Sankpal NV. Production of organic acids and metabolites of fungi for food industry. In: Khachatourians GG, Arora DK, editors. Applied Mycology and Biotechnology: Agriculture and Food Production: Elsevier Science B.V. Amsterdam; 2001:387-423.

49. Quitmann H, Fan R, Czermak P. Acidic organic compounds in beverage, food, and feed production. Adv Biochem Eng Biotechnol. 2014;143:91-141.

50. Smid EJ, Kleerebezem M. Production of aroma compounds in lactic fermentations. Ann Rev Food Sci Technol. 2014;5:313-26.

51. Markiewicz-Keszycka M, Czyzak-Runowska G, Wojtowski J, Jozwik A, Pankiewicz R, Leska B, Krzyzewski J, Strzalkowska N, Marchewka J, Bagnicka E. Influence of stage of lactation and year season on composition of mares' colostrum and milk and method and time of storage on vitamin C content in mares' milk. J Sci Food Agric. 2015;95(11):2279-86.

52. Comasio A, Harth H, Weckx S, De Vuyst L. The addition of citrate stimulates the production of acetoin and diacetyl by a citrate-positive Lactobacillus crustorum strain during wheat sourdough fermentation. Int J Food Microbiol. 2019;289:88-105.

53. Dudley EG, Steele JL. Succinate production and citrate catabolism by Cheddar cheese nonstarter lactobacilli. J Appl Microbiol. 2005;98(1):14-23.

54. Jayaram VB, Cuyvers S, Verstrepen KJ, Delcour JA, Courtin CM. Succinic acid in levels produced by yeast (Saccharomyces cerevisiae) during fermentation strongly impacts wheat bread dough properties. Food Chem. 2014;151:421-8.

55. Gadaga TH, Mutukumira AN, Narvhus JA. The growth and interaction of yeasts and lactic acid bacteria isolated from Zimbabwean naturally fermented milk in UHT milk. Int J Food Microbiol. 2001;68:21-32.

56. Kozhakhmetova Z, Kasenova G. Selection of lactic acid bacteria and yeast for koumiss starter and its impact on quality of koumiss. Appl Technol Innov. 2014;9(4):138-42.

57. Narvhusa JA, Gadaga TH. The role of interaction between yeasts and lactic acid bacteria in African fermented milks: a review. Int J Food Microbiol. 2003;86:51-60.

58. Viljoen BC. The interaction between yeasts and bacteria in dairy environments. Int J Food Microbiol. 2001;69:37-44.

59. Smid EJ, Lacroix C. Microbe-microbe interactions in mixed culture food fermentations. Curr Opin Biotechnol. 2013;24(2):148-54.

60. Carr A, Diener C, Baliga NS, Gibbons SM. Use and abuse of correlation analyses in microbial ecology. ISME J. 2019;13:2647-55.

61. Álvarez-Martín P, Flórez AB, Hernández-Barranco A, Mayo B. Interaction between dairy yeasts and lactic acid bacteria strains during milk fermentation. Food Control. 2008;19(1):62-70.

62. Millar BC, Xu J, Earle JAP, Evans J, Moore JE. Comparison of four rDNA primer sets (18S, 28S, ITS1, ITS2) for the molecular identification of yeasts and filamentous fungi of medical importance. Br J Biomed Sci. 2016;64(2):84-9.
63. Stielow JB, Lévesque CA, Seifert KA, Meyer W, Irinyi L, Smits D, Renfurm R, Verkley GJM, Groenewald M, Chaduli D, et al. One fungus, which genes? Development and assessment of universal primers for potential secondary fungal DNA barcodes. Persoonia. 2015;35(1):242-63.

64. Shen W-H, Hohn B. DMSO improves PCR amplification of DNA with complex secondary structure. Trends Genet. 1992;8(7):228.

65. Razafimandimbison SG, Kellogg EA, Bremer B. Recent origin and phylogenetic utility of divergent ITS putative pseudogenes: a case study from Naucleeae (Rubiaceae). Syst Biol. 2004;53(2):177-92.

66. Chen YF, Wang JC, Yun ZY. Study on organic acids in traditionally fermented milk by HPLC. Chin Dairy Indust. 2007;35(1):54-8.

\section{Publisher's Note}

Springer Nature remains neutral with regard to jurisdictional claims in published maps and institutional affiliations.

\section{Ready to submit your research? Choose BMC and benefit from:}

- fast, convenient online submission

- thorough peer review by experienced researchers in your field

- rapid publication on acceptance

- support for research data, including large and complex data types

- gold Open Access which fosters wider collaboration and increased citations

- maximum visibility for your research: over $100 \mathrm{M}$ website views per year

At BMC, research is always in progress.

Learn more biomedcentral.com/submissions 